\title{
Oyun algısı ölçeğinin geliştirilmesi: Geçerlik ve güvenirlik çalışması
}

\section{Developing play perception scale: Validity and reliability study}

\begin{abstract}
Makale Geçmişi
Geliş : : 21 Nisan 2019

Düzeltme : 4 Ağustos 2019
\end{abstract}

Kabul : 23 Aralik 2019

\section{Makale Türü}

Araştırma Makalesi

\section{Article History}

Received : 21 April 2019

Revised : 4 August 2019

Accepted : 23 December 2019

\section{Article Type}

Research Article

\author{
Gökhan Güneş ${ }^{1}$, Belma Tuğrul², Esra Demir Öztürk ${ }^{3}$
}

Öz: $\mathrm{Bu}$ araştırmanın amacı oyuna ilişkin algıların incelenmesini hedefleyen bir ölçme aracının geliştirilmesidir. Bu araştırma kapsamında Oyun Algısı Ölçeği (OAÖ) her ne kadar okul öncesi öğretmen adaylarının katılımı ile geliştirilmiş olsa da ölçeğin öğretmenler, ebeveynler, pedagoglar ve alan uzmanları gibi çeşitli çalışma gruplarına da uygulanabilecek özellikler taşıması hedeflenmiştir. OAÖ pilot ve ana uygulama olmak üzere iki aşamada geliştirilmiştir. Çalışma, bir devlet ve bir vakıf üniversitesinin Eğitim Fakültesi Okul Öncesi Öğretmenliği bölümünde öğrenim gören 240 öğretmen adayı ile 2017/2018 ve 2018/2019 akademik yıllarında yürütülmüştür. Yapılan analizler sonucunda, 20 maddeden oluşan beşli likert tipteki ölçeğin; "oyunun işlevi ve oyunda ilgi/merak/keşif”, "oyunun özgünlüğü ve amacı" ile "oyunun doğası ve kaynağı" olmak üzere üç faktörlü bir yapıya sahip olduğu belirlenmiştir. Maddetoplam korelasyon katsayılarının $.157 \leq \mathrm{r} \leq .656$ aralığında değiştiği tespit edilmiş ve Cronbach alpha değeri de .728 olarak hesaplanmıştır. Elde edilen sonuçlar, geliştirilen ölçeğin araştırmalarda kullanılabilecek geçerli ve güvenilir bir ölçüm aracı olduğunu göstermektedir.

Anahtar Kelimeler: Okul öncesi eğitim, Oyun, Oyun Algısı Ölçeği, Ölçek geliştirme

Abstract: The purpose of this study was to develop a measurement tool to examine perceptions about the play. Although the Play Perception Scale (PPS) was developed with the participation of preschool teacher candidates, it was aimed to have features that could be applied to various working groups such as teachers, parents, pedagogues and field experts. The development of PPS was carried out in two stages as pilot and main application. The study was conducted in 2017/2018 and 2018/2019 academic years with 240 prospective teachers attending in the Preschool Teaching Department of the Faculty of Education of a state and a foundation university. As a result of the analysis, it was determined that the five-point Likert-type scale consisting of 20 items which had three-factor structures as "the function of the play and interest/curiosity/discovery in the play", "originality and purpose of the play" and "the nature and source of the play". Item-total correlation coefficients varied between $.157 \leq \mathrm{r} \leq .656$ and Cronbach alpha value was calculated as .728 . The obtained results show that the developed scale is a valid and reliable measurement tool that can be used in studies.

Keywords: Preschool education, Play, Play Perception Scale, Scale development 


\section{SUMMARY}

\section{Introduction}

Mental development depending on the actions of the individual starting from the moment they communicate with the outside world (Park, 2019). The play performs stimulation in the mind and enables children to develop in cognitive skills that are basic, such as attention, observation, memory, reasoning, and decision-making. Through play, children see that there are different thoughts and preferences, and experience the difference of roles in society (Gander and Gardiner, 2001). At the same time, children gain the ability to use language with play, to communicate with their environment, to acquire new friendships, to wait for their order, to be able to control themselves and to behave according to situations (Lockhard, 2010). Even in the most unfavorable conditions, the play offers children the opportunity to have fun and beautifies their lives (Boss, 2014). The philosophical foundations and inferences of the development of epistemic cognition, knowledge, recognition and learning, in the context of play which has a strong and decisive role on all areas of development of children is thought to give a new philosophical understanding beyond the traditional approaches (learning, teaching, problem solving, creativity, recognition and evaluation of children) of the play. Especially, the determinative effect of teachers' epistemological beliefs and practices especially in the early years of children presents important data about the structure of the child's knowledge, learning and value system (Lunn Brownlee, Scholes, Walker, and Johansson, 2016). In this context, examining the dynamics that are based on epistemic cognition of the play only with the subdimensions of epistemological view, may not adequately explain the philosophical thoughts developed in the context of the play.

It is known that play perceptions which reflects subjective values, are not only based on social-cultural effects, beliefs, functionality, benefits or expectations (academic, social and emotional development) but also personal play experiences, play background story and play memories and. In this regard, it is thought that examining the perceptions of the play reflecting the subjective values through the philosophical structure of the play within the context of its epistemic roots is important for evaluating the personal perspectives of the play. Although the measurement tool developed within the scope of this research was carried out with the participation of preschool teacher candidates, the scale was aimed to have features that could be applied to various working groups. In other words, the measurement tool developed; various groups such as teachers, prospective teachers, parents, pedagogues and field experts are intended to enable the perception of play. In this context, the purpose of this study was to develop a measurement tool to examine perceptions about the play.

\section{Method}

This research is a scale development study which includes validity and reliability analyzes of the Play Perception Scale (PPS), prepared for the purpose of examining the perceptions on philosophical structure of play at the context of play's epistemic roots. PPS was carried out in two stages as pilot and main 
application. The study group of the research consisted of 240 students who are attending in Preschool Education Department of Faculty of Education consisting of one State and one Foundation University. Twelve expert opinions were consulted for the validity of the scale and the items were found to have adequate coverage validity. The conformity tests with parametric tests were determined by KolmogorovSmirnov and Shapiro Wilk and Skewness-Creation coefficients were calculated. Exploratory factor analysis (EFA) method was used to examine the validity of PPS. For the determination of reliability, item analyzes and Cronbach Alpha were calculated.

\section{Results}

It was observed that PPS was suitable for the factor analysis for construct validity $[\mathrm{KMO}$ value $=.794>$ .600 , Bartlett Test Chi square 823.837 and $\mathrm{p}=.000]$. Factor analysis of PPS was found to have a three-factor structure according to the Screeplot chart and the levels of binding of substances to factors were between .390 and .772. Based on the conceptual approaches such as the sub-dimensions of the PPS, the epistemic sub-dimensions associated with the scale items, and the characteristics, structure and effect of the play, namely, "function of the play and interest/curiosity/discovery in the play", "the originality and purpose of the play", and "nature and source of play". The Cronbach's Alpha value was found to be .728 in the analysis for the internal consistency coefficient of the PPS. Thus, it can be seen that developed PPS is a valid and reliable measurement tool that can be used in research.

\section{Conclusion and Discussion}

The sub-dimensions that generate the PPS are defined as "the nature of the play and its source" with the "function of play and interest/curiosity/discovery in the play", the "originality and purpose of the play". The nature of information highlighted in epistemology literature in the definition of sub-dimensions of PPS (Elder, 2002; Güneş and Bat1, 2008), the nature of knowledge, the source of knowledge and authority/accuracy (Hofer and Pintrich, 1997), understanding and evaluating information (Greene, Sandoval and Bråten, 2016), taking into account the epistemic thinking dimensions such as change of knowledge, processes of knowledge generation and the nature of knowledge/knowledge, effort in the processes of authority/truth and knowledge (Elder, 2002; Schommer, 1994). In the studies conducted, the play provides the development of decision-making and problem-solving skills of children (Ramani, 2005), to use the energy of mind for a long time (Hirsh and Golinkoff, 2008), to improve the ability of imitation and creativity (Pellegrini, 2009) and the speed of reasoning and processing (Mackey, Hill, Stone and Bunge, 2011). These features played an important role in shaping the sub-dimensions that reflect the epistemological structure of the play which the PPS intended to study. From this point, sub-titles such as "play functionality and play interest/curiosity", "play specificity and purpose" and "nature and source of the play" where PPS sought an answer are more holistic in personal epistemic cognitive development and also allow for examination with a purposeful perspective. The sub-dimensions of PPS will contribute to the theoretical structure of the play, strengthen the epistemic aspect of the play and it can be said that the play will develop personal epistemic cognition levels based on the plays. 


\section{GİRIŞ}

Epistemolog ve Biyolog olan Jean Piaget (1964), yeni doğanların çoğu hareketini oyun olarak nitelemekte, çevreyi tanıma ve keşfetme süreci olarak tanımlamaktadır. Çocuğun tüm bu uğraşıları ona zevk vermekte, döngüselliği ortaya çıkarmakta ve ilk zihinsel kombinasyonları oluşturarak biliş dünyasını genişletmektedir (Kostelnik, Soderman ve Whiren, 2007). Vygotsky (1967); oyunu, soyut düşünceyi geliştiren ve çocuğun çevresiyle mücadelesini kolaylaştıran etkinliklerden oluşan bir bütün olarak tanımlamakta ve erken yılların temeli olarak nitelemektedir (Bodrova ve Leong, 2010). Tuğrul (2014)'a göre oyun, çocuğun öğrenme dili ve kişisel keşif alanıdır. Bruner (1975)'a göre oyun, probleme çözme sürecini içerir. MacDonald (2011), oyunun çocuğun öğrenmesini kolaylaştırdığını vurgulamaktadır. Montessori (1992), oyunun çocuğun en temel işi olduğunu belirtir. Montaigne ise, oyunu çocuk için ciddi uğraşı olarak tanımlar (Öztürk, 2010). Oyuna ilişkin çok farklı tanımlar olmakla beraber genel olarak oyun; zevk veren, kendiliğinden gelişen, rahatlatan, eğlendiren aynı zamanda geliştiren etkinlikleri ifade etmektedir. Bu özellikler oyunu çocuk için vazgeçilmez kılmaktadır (Bodrova ve Leong, 2013; Ginsburg, 2007). Çocukların tüm gelişim alanlarına etki eden oyun, çocuğa çok çeşitli kazanımlar sağlamaktadır. Öncelikli olarak zihinsel gelişim, bireyin dış dünyası ile iletişime geçtiği anda başlamakta eylemlerine bağlı olarak gelişim göstermektedir (Park, 2019). Oyunu deneyimlemeyen ve oyundan mahrum olan çocukların bilişsel ve sosyal-duygusal gelişimleri zarar görmektedir (Pellegrini, 2009; Saracho, 1999). Oyun, zihinde uyarılmayı gerçekleştirmekte ve çocukların dikkat, gözlem, hafıza, akıl yürütme, karar verme gibi temel olan bilişsel becerilerde gelişimini sağlamaktadır. Oyun yoluyla çocuklar, farklı düşünce ve tercihlerin olduğunu görmekte, toplumda rollerin farklılaştığını deneyimlemektedirler (Gander ve Gardiner, 2001). Aynı zamanda çocuklar oyunla dili kullanabilme, çevresi ile iletişim kurma yeni arkadaşlıklar edinme, sırasını bekleme, kendini kontrol edebilme ve durumlara uygun davranışlar sergileyebilme becerileri kazanmaktadır (Lockhard, 2010). Buradan hareketle çok yönlü bir özelliğe ve evrenselliğe sahip olan oyununun, çocuk gelişiminin hem bir göstergesi hem de geliştiricisi olduğu söylenebilir.

Çocuklar oyunla bilgi ve becerilerini artırmaktadır. Oyun yoluyla çocuk çevreyi ve doğayı tanımakta, doğadaki her şeyi oyun yoluyla keşfetmektedir. Çocukların doğasında var olan merak duygusu ile araştırma, akıl yürütme, neden sonuç ilişkisi kurma ve problem çözme becerisini ortaya çıkarmaktadır. Oyun, çocukların deneyim, bilgi ve anlayışını birleştiren bir olgu olmasının yanı sıra bilginin oluşturulması ve kazanılmasında etkin rol oynamaktadır (Ginsburg, 2007; Lockhard, 2010; Saracho, 1999; Sutton-Smith, 1971). Karmaşık bir yapıya sahip olan oyun, çocuklarda dogmatik olmayan, değişebilen, farklı sonuçları ortaya koyabilen bir düşünce yapısı oluşturmaktadır. $\mathrm{Bu}$ yönüyle Rousseau, oyunun yaparak yaşayarak öğrenmeyi sağladığını belirtmektedir. 
Hofer (2001) bireysel epistemolojik inançların temelinde bilginin tanımı, yapılandırılması ve değerlendirilmesi olduğunu belirtmektedir. Schommer'da (1990) bilgi felsefesi kapsamında bilginin sınırları, kesinliği, bilginin kaynağı ile öğrenmenin kontrolünü ve hızının incelenmesi gerektiğini vurgulamaktadır. Küçük çocukların epistemik yaklaşımlarının dogmatik bir yapıda olduğu bilinse de (Cadinu ve Kiesner, 2000; Güneş, Şahin, Taşdan-Berksoy ve Erkan, 2018; Mascaro ve Morin, 2015; Taşdan-Berksoy ve Güneş, 2018), artan hayat deneyimleri yardımıyla kavramsal bilgilerinin skeptik bir yapıya doğru evrildiği rapor edilmektedir (Conley, Pintrich, Vekiri ve Harrison, 2004; Kienhues, Bromme ve Stahl, 2008; King ve Kitchener, 1994; Kuhn, 1991; Rodriguez ve Cano, 2007). Kuhn, Cheney ve Weinstock (2000) çocukların dört yaşından itibaren epistemolojik görüşlerini yansıtan iddia ve söylemlerine dikkat çekerek bu yaş grubunu epistemik olgunlaşma açısından kritik dönem olduğunu savunmaktadır. Epistemik biliş gelişiminde, üst düzey düşünme becerilerinin etkisi vurgulanarak (Bendixen ve Hartley, 2003), düşünme becerilerinde önemli bir rol oynayan öğrenmenin kontrolü, öğrenmenin hızı ve öğrenme becerisinin genetik mi yoksa çabaya mı dayalı olduğuna ilişkin görüşler (Schommer, 1994), epistemik biliş gelişiminin yapısı ve düzeyi hakkında fikir vermektedir. Epistemik biliş, epistemolojinin araştırma konularından olan bilginin kaynağ1, değerlendirilmesi, kanıtlar, doğruluk, kavrama ve açıklama gibi süreçlerle ilişkili bir ağ olarak değerlendirilmektedir (Chinn, Buckland ve Samarapungavan, 2011). Bu yönü ile bireysel epistemik biliş, epistemolojik görüşlerden ve bilgi ile ilgili tüm bilişsel süreçlerden oluşan bütünsel bir yap1 sergilemektedir (Barger ve Linnenbrink-Garcia, 2017; Chinn vd, 2011; Greene, Azevedo ve Torney-Purta, 2008). Bu noktada, epistemik biliş gelişiminin, öğrenme-öğretme, başarı ve eleştirel düşünme gibi becerilerden (Kuhn, 2016; Lunn Brownlee, Ferguson ve Ryan, 2017) bilgiyi kullanma ve araştırmalarda doğru bilgilere yer verebilme yeteneğine kadar yaygın bir etki alanına sahip olduğu vurgulanmaktadır (Bendixen, 2002; Kienhues, Ferguson, ve Stahl, 2016).

Bilginin felsefi kökenleri; sınırları, kesinliği, değişimi, gelişimi ve üretme süreçleri, insanlığın bilgiye verdiği anlamı, aktarımına gösterdiği önemi ve yayılması noktasında izlediği politikaları düzenleyerek şekillendirmektedir. Benzer şekilde; insanlığın en eski uğraşı, çevreyi tanıma ve iletişim kurma aracı, düşünme ve yaratma yetisini oluşturan, yansıtan ve geliştiren oyunda, ilk öğrenmelerin, öğrenmeye ilişkin tutum ve davranışların gelişiminde belirleyici bir etkiye sahiptir (Salmon ve Lucas, 2011; Schommer, 1990; Sutton- Smith, 1971). Bu bağlamda, oyunun felsefi kökenlerinin başka bir ifade ile oyunun epistemik yapısının incelenmesinin, bilgi ile oyun kavramlarının bütüncül, tamamlayıcı ve ilişkisel bir yaklaşımla değerlendirilmesine katkı sağlayacağı düşünülmektedir. 


\section{Araştırmanın Amacı ve Önemi}

Epistemik biliş gelişiminin bilgiye, bilmeye ve öğrenmeye yönelik felsefi temelleri ve çıkarımlarının, çocukların tüm gelişim alanları üzerinde güçlü ve belirleyici bir role sahip olan oyun bağlamında incelenmesinin, oyuna ilişkin geleneksel yaklaşımlann (öğrenme, öğretme, problem çözme, yaratıcılık, çocuğu tanıma ve değerlendirme) ötesinde yeni bir felsefi anlayış kazandıracağı düşünülmektedir. Dinamik ve skeptik bir yapıya sahip olan oyun ve oyuna ilişkin algıların oluşumu, bireylerde bilgi ve bilgiye ilişkin algıların oluşumu ile paralellik gösteren bir sürece işaret etmektedir (Bodrova ve Leong, 2013; Kostelnik, Soderman ve Whiren, 2007). Bunun yanı sıra, sübjektif değerler içeren oyuna ilişkin algıların sadece sosyal-kültürel etkiler, inançlar, oyunun işlevselliği, oyunun yararı, oyundan beklentiler (akademik, sosyal, duygusal gelişim) değil aynı zamanda bireylerin oyun deneyimleri, oyun özgeçmişleri, oyun hatıraları ve oyun okur-yazarlığı gibi etkenlere dayandığı bilinmektedir. Kişisel olan oyun anıları, oyun özgeçmişleri, tavırlar, tutumlar ve değer yargıları arasında özel ve insan gelişimini etkileyen güçlü bir bağ olduğu bilinmektedir (Burr, Atkins, Bertram, Sears ve McGinnis, 2019; Kjørholt, Matafwali ve Mofu, 2019; Sandberg, 2003). Ayrıca oyun anılarının kişisel gizlilik ve özelliğinden dolayı sosyal yaşamda geliştirilen davranışların şekillenmesinde belirleyici bir rol oynadığ1 belirtilmektedir (Eck, 2017). Sandberg'e göre (2001) oyun anılarını; 3-6 yaş, 7-12 yaş ve 13-18 yaş aralı̆̆ında kategorize etmek mümkündür. Oyun anılarının kategorize edilmesinin temelini oluşturan çalışmalarda; oyuncakların, oyun arkadaşı olan evcil hayvanların, ailelerin, akranların ve fiziksel çevrenin, bireylerin oyun hatırlarını oluşturan başlıca ögeler olduğu rapor edilmiştir (Henninger, 1994; Sandberg, 2003). Oyun anıları ve içerdikleri ögelerin bireylerin oyun algısının gelişiminde de önemli bir rol oynadığı belirtilmektedir (Henninger, 1994). Buradan hareketle; oyun alg1sı oluşumunu etkileyen oyun hatıraları, oyun özgeçmişi ve içerdiği fiziksel ögeler (oyuncak, arkadaş/evcil hayvan ve mekan) dışında, bireylerin oyun algısına yönelik felsefi yaklaşımlarının incelenmesi, çalışmanın başlıca önemi olarak görülmektedir.

Bu araştırma kapsamında ölçme aracı her ne kadar okul öncesi öğretmen adaylarının katılımı ile geliştirilmiş olsa da ölçeğin çeşitli çalışma gruplarına da uygulanabilecek özellikler taşıması hedeflenmiştir. Başka bir ifade ile geliştirilen ölçme aracının; öğretmenler, aday öğretmenler, ebeveynler, pedagoglar ve alan uzmanları gibi çeşitli grupların oyun algısının belirlenmesine olanak sağlayacak nitelikte olması amaçlanmıştır. Bu bağlamda, oyun algılarının incelenmesinde kullanılabilecek geçerli ve güvenilir bir ölçme aracının geliştirilmesi, araştırmanın amacı olarak belirlenmiştir. 


\section{YÖNTEM}

$\mathrm{Bu}$ araştırma oyun algılarının incelenmesi amacıyla hazırlanan Oyun Alg1sı Ölçeğinin (OAÖ) geçerlik ve güvenirlik analizlerini içeren bir ölçek geliştirme çalışmasıdır.

\section{Çalışma Grubu}

Araştırmanın çalışma grubunu, 2017-2018 ve 2018-2019 akademik yılları arasında bir Devlet ve bir Vakıf Üniversitesi Eğitim Fakültesi Okul Öncesi Öğretmenliği Bölümüne devam eden 240 aday öğretmen oluşturmaktadır. Ölçeğin geliştirilme çalışması pilot ve ana uygulama olmak üzere iki aşamadan oluşmaktadır. Aday ölçek, pilot uygulamada 68, ana uygulamada ise 172 öğretmen adayına uygulanmıştır. Ana uygulamada yer alan katılımcıların 129'u kadın, 43’ü ise erkek öğretmen adayıdır. Çalışma grubunun \%41'ini birinci sınıfa, \%49’unu ikinci sınıfa, \%37'sini üçüncü sınıfa ve \%45’ini de dördüncü sınıfa devam eden katılımcılar oluşturmaktadır. Örneklemin sınıf düzeyinde dengeli bir dağılıma sahip olduğu görülmektedir.

Çalışma kapsamında katılımcılara araştırmanın gönüllülük esasına göre yürütüldüğü ve istedikleri zaman çalışmanın herhangi bir aşamasında araştırmadan ayrılabilecekleri belirtilmiştir.

\section{Analiz Yöntemleri}

Ölçeğe ilişkin güvenirlik-geçerlilik çalışmaları bağlamında, kapsam geçerliliğinin belirlenmesi için Lawshe Tekniği (1975) kullanılmıs, ölçeğin parametrik testlere uygunluğunun test edilmesi için, normallik testlerinden Kolmogorov-Smirnov, Shapiro-Wilk ile Çarpıklık-Basıklık (SkewnessKurtosis) katsayılarının hesaplanması gerçekleştirilmiştir. Yap1 geçerliliğinde kullanılacak faktör analizi testlerine uygunluğu için KMO ve Bartlett Testleri kullanılmış, yapı geçerliliğinin analiz edilmesi için açımlayıcı faktör analizi (Explorer factor analyses) yapılmıştır. Güvenirlik için madde analizleri (Alt-üst grup ortalama puan farkı, madde-toplam puan korelasyonu) ve iç tutarlılık katsayısı Cronbach Alpha belirlenmiştir.

\section{OAÖ Geliştirilme Süreci}

\section{Kapsam geçerliliği}

Aday ölçeğin kapsam geçerliliği için 12 uzmandan görüş istenmiştir. Ölçme değerlendirme alanından iki, epistemoloji alanından iki, beş yıllık deneyime sahip bir okul öncesi öğretmeni ve 
çocuk gelişimi alanından da yedi uzman ölçek maddelerinin kapsam geçerliliğine ilişskin görüş belirtmiştir. Maddelerin kapsam geçerliliği Lawshe Tekniği (1975) kullanılarak ölçülmüştür.

Kapsam Geçerlilik Ölçütü (KGÖ) için:

$\mathrm{N}_{\mathrm{G}}=$ Maddeye uygun diyen uzman sayıs

$\mathrm{N}=$ Maddeye görüş belirten toplam uzman sayısı

$\mathrm{KGÖ}=\left[\mathrm{N}_{\mathrm{G}} /(\mathrm{N} / 2)\right]-1$ formülü kullanılmaktadır. Araştırmacılar tarafindan oluşturulan 30 maddelik soru havuzuna ilişkin 12 uzmandan alınan görüşlerle elde edilen maddelerin KGÖ Tablo 1' de sunulmuştur.

Tablo 1. OAÖ Lawshe (1975) madde KGÖ sonuçları

\begin{tabular}{cllll}
\hline Maddeler & Gerekli & Uygun-Yetersiz & Gereksiz & Kapsam Geçerlilik Oranı (KGO) \\
\hline 1 & 12 & - & - & 1.00 \\
2 & 12 & - & - & 1.00 \\
3 & 10 & 1 & 1 & .67 \\
4 & 11 & 1 & - & .83 \\
5 & 10 & 1 & - & .67 \\
6 & 11 & 1 & - & .83 \\
7 & 12 & - & - & 1.00 \\
8 & 12 & - & - & 1.00 \\
9 & 11 & - & 1 & .83 \\
10 & 10 & 2 & - & .67 \\
11 & 10 & 1 & 1 & .67 \\
12 & 11 & - & 1 & .83 \\
13 & 10 & - & 2 & .67 \\
14 & 12 & - & - & 1.00 \\
15 & 11 & - & 1 & .83 \\
16 & 10 & 2 & - & .67 \\
17 & 12 & - & - & 1.00 \\
18 & 10 & 2 & - & .67 \\
19 & 12 & - & - & 1.00 \\
20 & 10 & 2 & - & .67 \\
21 & 11 & - & 1 & .83 \\
22 & 10 & 2 & - & .67 \\
23 & 11 & 1 & - & .83 \\
24 & 12 & - & - & 1.00 \\
25 & 11 & 1 & -83 \\
26 & 12 & - & - & 1.00 \\
27 & 12 & - & - & 1.00 \\
28 & 11 & 1 & - & .07 \\
29 & 10 & 2 & - & \\
30 & 12 & - & -00 \\
\hline
\end{tabular}


Tablo 1'de, aday ölçek için oluşturulan madde havuzunda yer alan tüm maddelerin KGÖ değerlerinin 12 uzman için $\geq .56$ olması, belirlenen maddelerin aday ölçek için yeterli kapsam geçerliliğine sahip olduğunu göstermektedir (Lawshe, 1975).

Ölçeğin geliştirilme sürecinde, pilot uygulama 68, ana uygulama ise 172 katıllımc1 ile yürütülmüştür. Ölçek geliştirme çalışmalarında çok değişkenin bulunmadığı ölçüm araçları için Büyüköztürk (2002) 100 ile 200 arasındaki katılımcının yeterli olduğunu belirtilmektedir. Ayrıca genel bir kural olarak, ana uygulamanın, ölçek madde sayısının beş katından $(30 * 5=150)$ fazla katılımcı ile yürütülmesi, ölçek geliştirilmesi için yeterli örneklem sayısına ulaşıldığını göstermektedir (Büyüköztürk, Kılıç Çakmak, Akgün, Karadeniz ve Demirel, 2014; Tavşancıl, 2006).

\section{OAÖ Pilot Uygulama}

\section{OAÖ pilot uygulama normallik testleri sonuçları}

Pilot uygulamada, öncelikle aday ölçeğin parametrik testlere uygun olup olmadı̆̆ının anlaşılması için normallik testleri yapılmıştır. Katılımcılardan birinin uç değerde yanıtlar verdiği tespit edilerek bu yanıtlar analizlere dâhil edilmemiştir. Aday ölçüm aracına ilişkin betimsel istatistik ve normallik test sonuçları Tablo 2' de sunulmuştur.

Tablo 2. OAÖ betimsel istatistik ve normallik test sonuçları

\begin{tabular}{llllllllll}
\hline & Min. & Max. & Sd & S & $\overline{\boldsymbol{x}}$ & PKolmogorov-Smirnov & pShapiro-Wilk & Çarp1kl1k & Basıkl1k \\
\hline OAÖ & 81.00 & 121.00 & 8.08 & 65.30 & 100.06 & .200 & .885 & .098 & -.01 \\
\hline
\end{tabular}

$\mathrm{N}=67$

Tablo 2'de ölçeğin toplam puanı üzerinden hesaplanan normallik test sonuçlarından pKolmogorov-Smirnov ile pshapiro-Wilk $\geq .05$ ve çarpıklık-basıklık katsayılarının da normal dağılım değer aralığında olduğu görülmektedir $[-\mathrm{z}=-1.95 \leq \mathrm{z}($ çarpılklık=.098, basıklık=-.10) $\leq+\mathrm{z}=+1.95]$ (McKillup, 2012; Tabachnick ve Fidell, 2001). Normallik test sonuçlarına göre ölçeğin parametrik testlere uygun normal dağılım gösteren bir ölçüm aracı özelliğinde olduğu söylenebilir (Howitt ve Cramer, 2011). Ölçeğin ortalama puanı 30 madde üzerinden 100.06, varyansı 65.30 ve standart sapma değeri de 8.08 olarak hesaplanmıştır.

\section{OAÖ pilot uygulama güvenirlik sonuçları}

Pilot uygulamada hesaplanan iç tutarlılık katsayısı .647 bulunmuştur. Cronbach Alpha katsayısının .70'den küçük olmasına rağmen, az sayıdaki örneklem grubuna ilk kez uygulanmış olması (Büyüköztürk, 2015), bunun yanı sıra .50'den büyük olduğu için yeterli oranda güvenilir kabul 
edilmesi (Schmitt, 1996) ve eğitim alanında ölçek kullanılarak yapılan araştırmaların çoğunda .60'ın yeterli görülmesi (Taber, 2018), ölçeğin ana uygulamada kullanılabilecek güvenirlikte olduğunu göstermektedir.

\section{OAÖ pilot uygulamada tespit edilen geçerliliğe ilişkin problemler}

Pilot uygulama sonrası yapılan ön-analizlerde, ölçeğin iç tutarlılık katsayısı (Cronbach Alpha), maddelerin faktör yük değerleri (extraction), maddelerin ölçeğe anlamlı katkısı (alt-üst grup ortalama puan farklarına dayalı madde analizi sonuçları) ve maddelerin ölçeğe olan olumlu katkıları (madde-toplam korelasyon katsayıları) değerlendirildiğinde, 10 maddenin hiçbir güvenirlik ve geçerlilik testinden geçemediği tespit edilmiştir. Geliştirilmesi amaçlanan ölçüm aracında güvenirlik ve yapısal geçerlilik problemine neden olduğu saptanan bu maddeler, pilot uygulamalara katılan deneklerden tesadüfi seçilen 15 katılımcı ile yüz yüze görüşülerek tekrar sorulduğunda, katılımcıların maddeleri anlamadıkları ve aynı amaca hizmet eden tekrarlı ters maddelerde çelişkili yanıtlar verdikleri anlaşılmıştır. Yapılan madde analizleri ve katılımcılarla gerçekleştirilen görüşmeler doğrultusunda aday ölçekten bu 10 maddenin çıkarılarak ana uygulamaya geçilmesine karar verilmiştir.

\section{BULGULAR ve TARTIŞMA}

$\mathrm{Bu}$ kısımda ölçüm aracının ana uygulamasında elde edilen bulgulara yer verilmiştir. Ölçek ana uygulamasında katılımcılardan dördünün ölçek toplam puanları uç değerlerin üzerinde olduğundan bu katılımcılara ait veriler kullanılmayarak analiz süreçleri 168 katılımcı üzerinden gerçekleştirilmiştir.

\section{OAÖ Geçerlilik Sonuçları}

Ana uygulama sonrası ölçeğin faktör analizine uygun olup olmadığının anlaşılması amacıyla yapılan KMO ve Bartlett testi sonuçları Tablo 3'de sunulmuştur.

Tablo 3. OAÖ ilişkin KMO ve Bartlett test sonuçları

\begin{tabular}{lllll}
\hline & Ölçüm değeri & Ki Kare & Sd & p \\
\hline KMO değeri & .794 & & & \\
Bartlett's Test of Sphericity değeri & & 823.837 & 190 & .00 \\
\hline
\end{tabular}

Tablo 3'de, KMO değeri=.794> .600, Bartlett Testi Ki Kare 823.837 ve p=.000 değerleri ile ölçeğin faktör analizine uygun olduğu görülmektedir (Field, 2000; Tabachnick ve Fideli, 2001). Ölçek maddelerinin faktör yük değerlerine ilişkin analiz sonuçları Tablo 4'de sunulmuştur. 
Tablo 4. OAÖ maddelerinin faktör yük değerlerine ilişkin sonuçlar

\begin{tabular}{ccc}
\hline Maddeler & Başlangıç değeri (initial) & Yük değeri (extraction) \\
\hline 1 & 1.000 & .302 \\
2 & 1.000 & .270 \\
3 & 1.000 & .493 \\
4 & 1.000 & .469 \\
5 & 1.000 & .441 \\
6 & 1.000 & .608 \\
7 & 1.000 & .402 \\
8 & 1.000 & .353 \\
9 & 1.000 & .535 \\
10 & 1.000 & .430 \\
11 & 1.000 & .425 \\
12 & 1.000 & .468 \\
13 & 1.000 & .376 \\
14 & 1.000 & .502 \\
15 & 1.000 & .452 \\
16 & 1.000 & .377 \\
17 & 1.000 & .197 \\
18 & 1.000 & .407 \\
19 & 1.000 & .308 \\
20 & 1.000 & .391 \\
\hline & & \\
\hline
\end{tabular}

Tablo 4'de maddelerin faktör yük dağglımları incelendiğinde madde 2 ve 17 'nin alt sınır olarak kabul edilen .30'dan küçük değerler almasına rağmen, diğer maddeler .302 ile .608 arasında değişen dağıllımlar göstermektedir. Ölçekte yer alan maddelerin büyük bir bölümünün yük değerlerinin kabul edilebilir alt sınırların (>.30) üzerinde olduğu görülmektedir (Büyüköztürk, 2002). Ölçeğin ana uygulama sonrası yapılan faktör analizine göre elde edilen Scree Plot grafiği şekil 1'de verilmiştir.

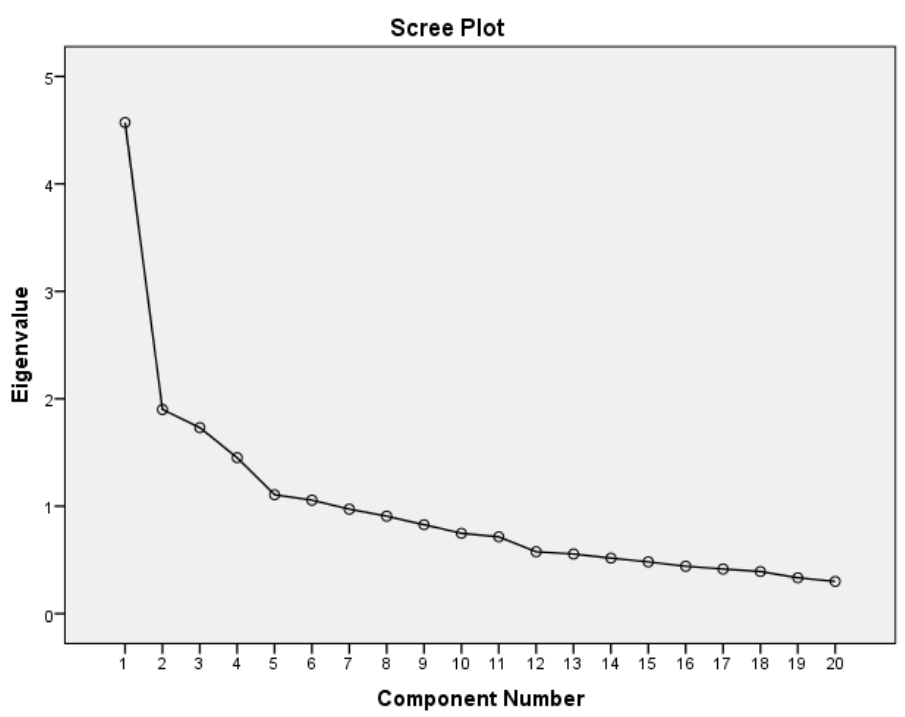

Şekil 1. OAÖ Scree Plot grafiği 
Şekil 1'de ölçeğin üç faktörlü bir yap1 sergilediği görülmektedir. Ölçekte yer alan maddelerin grafikte görülen faktörlere bağlanmasına ilişskin sonuçlar Tablo 5'de sunulmuştur.

Tablo 5. OAÖ faktör analizi sonuçları

\begin{tabular}{|c|c|c|c|c|c|c|}
\hline \multirow{2}{*}{\multicolumn{2}{|c|}{ Maddeler }} & \multicolumn{3}{|c|}{ Faktörler } & \multirow{2}{*}{ 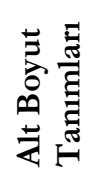 } & \multirow{2}{*}{ 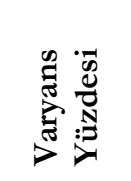 } \\
\hline & & 1 & 2 & 3 & & \\
\hline 6 & Oyun, çocuğun kendini ve dünyayı keşfetme aracıdır. & .772 & & & \multirow{10}{*}{ 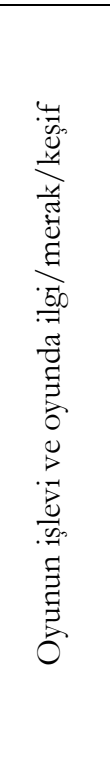 } & \multirow{10}{*}{$\% 22.86$} \\
\hline 3 & Oyun çocuklar için öncelikli olarak etkili bir öğretim aracıdır. & .701 & & & & \\
\hline 9 & $\begin{array}{l}\text { Çocuklar oyunlarında, basitten karmaşı̆̆a doğru ilerleyen bir } \\
\text { süreçte ustalaşırlar. }\end{array}$ & .694 & & & & \\
\hline 4 & Oyun çocuklar için öncelikli olarak eğlenceli bir uğraştır. & .678 & & & & \\
\hline 15 & $\begin{array}{l}\text { Çocuklar için en faydalı oyunlar, kendilerini ve dünyayı } \\
\text { keşfedebildikleri oyunlardır. }\end{array}$ & .665 & & & & \\
\hline 5 & $\begin{array}{l}\text { Oyun oynamanın en önemli yanı, çocuklara bilişsel açıdan } \\
\text { olumlu katkı sağlamasıdır. }\end{array}$ & .651 & & & & \\
\hline 12 & $\begin{array}{l}\text { Oyun oynamanın en güçlü yanı, oyun oynarken çocukların yeni } \\
\text { öğrenmeleri yapılandırmasıdır. }\end{array}$ & .632 & & & & \\
\hline 18 & $\begin{array}{l}\text { Oyun çocukların kişisel ilgi, gereksinim ve meraklarını } \\
\text { yansıttıkları ve kendi tecrübelerini kullanarak geliştirdikleri doğal } \\
\text { bir süreçtir. }\end{array}$ & .553 & & & & \\
\hline 2 & $\begin{array}{l}\text { Çocukların oyunlara gönüllü olarak katılması ve istediği şekilde } \\
\text { oynaması gerekir. }\end{array}$ & .490 & & & & \\
\hline 19 & $\begin{array}{l}\text { Çocukların gelişim alanlarındaki (bilişsel, duyuşsal, sosyal, ahlak, } \\
\text { dil ve cinsel gelişimlerinin) değişimleri oynayacakları oyunların } \\
\text { yapısını değiştirir. }\end{array}$ & .459 & & & & \\
\hline 14 & $\begin{array}{l}\text { Oyunların eğlenceli ve heyecan verici olması } \\
\text { öģ̧in } \\
\text { ogretmenlerinde oyunlara katılması gerekir. }\end{array}$ & \multicolumn{3}{|c|}{.656} & \multirow{6}{*}{ 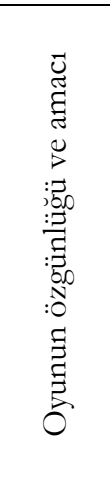 } & \multirow{6}{*}{$\% 9.50$} \\
\hline 16 & $\begin{array}{l}\text { Oyun oynama sürecinde çocuklarda oyunun beklenen olumlu } \\
\text { kazanımları gözlenmemesi, oyunun çocuk için yararlı olmadığını } \\
\text { gösterir. }\end{array}$ & \multicolumn{3}{|c|}{.581} & & \\
\hline 1 & Çocuklar oyun oynarken oyunun kurallarına uymak zorundadır. & \multicolumn{3}{|c|}{.534} & & \\
\hline & $\begin{array}{l}\text { Ö̆ğretmenin oyuna katılımı çocuğun oyundan yüksek yarar } \\
\text { sağlamasında önemlidir. }\end{array}$ & \multicolumn{3}{|c|}{.486} & & \\
\hline 17 & $\begin{array}{l}\text { Çocuğun oyundan en üst seviyede yararlanabilmesi için özel } \\
\text { oyuncaklara ve teknolojik materyallere gereksinimi vardır. }\end{array}$ & \multicolumn{3}{|c|}{.417} & & \\
\hline 13 & $\begin{array}{l}\text { Çocukların öğrenme süreçlerinde, oyun oynamak, } \\
\text { yapılandırılmıs etkinliklerden daha önemli bir rol oynar. }\end{array}$ & \multicolumn{3}{|c|}{.390} & & \\
\hline 11 & $\begin{array}{l}\text { Çocukların oyunlarda eğlenmesi için oyuna kendiliğinden dâhil } \\
\text { olması gerekmez. }\end{array}$ & & & .639 & \multirow{5}{*}{ 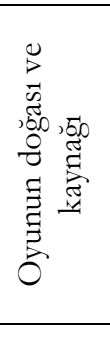 } & \multirow{4}{*}{$\% 8.66$} \\
\hline 20 & 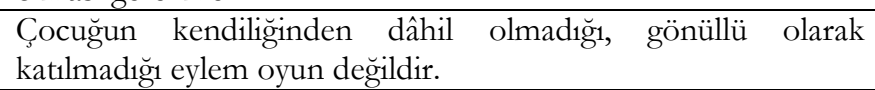 & & & .573 & & \\
\hline 8 & $\begin{array}{l}\text { Çocuklar yeni bir oyun keşfetmek yerine her zaman eğlenerek } \\
\text { oynadıkları oyunları oynamayı tercih ederler. }\end{array}$ & & & .572 & & \\
\hline 7 & $\begin{array}{l}\text { Oyunla ilgili bilgi kaynakları oyunun pedagojik değerini } \\
\text { anlayabilmemiz açssından nitelik ve nicelik olarak yeterlidir. }\end{array}$ & & & .556 & & \\
\hline Tol & lam Varyans Yüzdesi & & & & & $\% 41.02$ \\
\hline
\end{tabular}

Tablo 5'de maddelerin faktörlere bağlanma düzeylerinin .390 ile .772 arasında olduğu görülmektedir. Ölçekte yer alan 9 maddenin .60'ın üzerinde bir değerle ilgili faktöre bağlanması yüksek seviyeli bağlanmayı (Kline, 1994), ayrıca ölçekte yer alan sadece iki maddenin $\leq .45$ ’ın altında kalması, geliştirilen ölçeğin güçlü yapıda bir ölçüm aracı olduğunu göstermektedir (Büyüköztürk, 2015). Ana uygulama sonrası ölçüm aracının toplamda oyuna ilişkin algıya yönelik görüşleri 
açıklama varyansının \%40’n üzerinde olması, ölçüm aracının yeterli ve orta güçte bir açıklama varyansına sahip olduğunu göstermektedir (Kline, 1994). Bunun yanı sıra, ikinci ve üçüncü alt boyutta yer alan madde sayısı ve açıladıkları varyans değerlerinin birbirine yakın olması, ölçeğin dengeli bir yapıda olduğuna işaret etmektedir.

Tablo 5'de, Ölçeği oluşturan alt boyutlar “Oyunun işlevi ve oyunda ilgi/merak/keşif”, “Oyun özgünlüğü ve amacı" ile "Oyunun doğası ve kaynağı” olarak tanımlanmıştır. Ölçeğin alt boyutlarının tanımlanmasında, epistemoloji literatüründe vurgulanan bilginin doğası (Elder, 2002; Güneş ve Bat1, 2008), bilmenin doğası, bilginin kaynağı ve otorite/doğruluk (Hofer ve Pintrich, 1997), bilginin anlaşılması ve değerlendirilmesi (Greene, Sandoval ve Bråten, 2016), bilginin değişimi, bilgi üretme süreçleri ve bilginin/bilmenin doğası, bilgide otorite/doğruluk ve bilgi edinme süreçlerindeki çaba (Elder, 2002; Schommer, 1994) gibi epistemik düşünce boyutlarının önermeleri dikkate alınmıştır. Yapılan araştırmalarda oyunun; çocukların karar verme ve problem çözebilme becerilerinin gelişimini sağladığı (Ramani, 2005), zihin enerjisini uzun süreli kullanabilmesini (Hirsh ve Golinkoff, 2008), taklit becerisini ve yaratıcıllğını geliştirdiği (Pellegrini, 2009) ve akıl yürütme ve işlem hızını (Mackey, Hill, Stone ve Bunge, 2011) arttırdığ1 görülmüştür. Bu özellikler ölçeğin incelemeyi amaçladığı oyunun epistemolojik yapısını da yansıtan alt boyutların şekillenmesinde önemli bir rol oynamıştır.

Epistemik bilişin bilim adamı, mucit ve sanatçı kesiminin düşünüş biçimleri ile ilgilendiği belirtilmekte, eğitimsel süreçlerde ise öğrencilerin bilim insanlarının ve sanatçıların düşünme süreçlerini tartışmaları ve karşılaştırmaları vurgulanmaktadır (Seferoğlu ve Akbıyık, 2006). Ayrıca Hofer (2017) ne öğrenildiği ve nasıl öğrenildiği konularının da epistemik biliş çerçevesinde incelenmesi gerektiğini belirtmektedir. Öte yandan, son dönemde ise Greene vd., (2016) epistemik bilişin sadece bilim insanı ya da sanatçıların değil bireylerin formel ya da informel bilgiyi edinmelerini, anlamalarını, değerlendirmelerini ve değiştirme süreçlerini yansıttığını belirterek öğrenme çabalarını ve öğrenmeye ilişkin her türlü psikolojik yaklaşımı kapsadığını vurgulamaktadır. Bu bağlamda, oyuna ilişkin epistemik bilişin temel aldığ dinamikleri sadece epistemolojik görüş alt boyutlarıyla incelemek, oyun bağlamında geliştirilen felsefi düşünceleri yeterli düzeyde açıklayamayabilir. Buradan hareketle, ölçeğin yanıt aradığı "oyunun işlevseli ve oyunda ilgi/merak/keşif”, “oyunun özgünlüğü ve amacı” ve “oyunun doğası ve kaynağı” gibi alt başlıklar, oyuna ilişkin epistemik biliş gelişimlerinin daha bütünsel ve amaca yönelik bir bakış açısı ile oluşturulan algıların incelenmesine olanak tanıabilir. 
Önemle belirtmek gerekirse, oyun, çocukların doğasında var olan merak duygusunun ortaya çıtığı ve beslendiği, çocukların istedikleri anda ve durumda kendilerinin başlattığı oynarken zevk aldıkları bir etkinlik, yaşantısı için gerekli olan tüm bilgi ve becerileri deneyimlediği ve aktif olduğu alanı oluşturmaktadır (Bodrova ve Leong, 2013; MacDonald, 2001; Saracho, 1999). Ölçekte ortaya çıkan “oyunun işlevi ve oyunda ilgi/merak/keşif”, “oyunun özgünlüğü ve amacı” ve "oyunun doğası ve kaynağı” gibi alt boyutlar oyunun teorik yapısına katkı sunacağı, oyunun epistemik yönünü güçlendireceği ve bireylerin oyuna ilişkin algılarının şekillenmesinde epistemik açıdan tanımlayıcı ve geliştirici özellikler taşıyacağı söylenebilir. Bunların yanı sıra, genel olarak ölçekte oluşan her üç alt boyutunda, bireylerin yetişkinlerindeki sosyal davranışlarını ve gelişimlerini etkileyen oyun anıları ve özgeçmişleri (Burr ve diğ., 2019; Kjørholt ve diğ., 2019) ile ilişkili olduğu söylenebilir. Bireylerin oyun özgeçmişlerini oluşturan oyun deneyimleri, oyunlarına ilişkin anıları ve bu anıların oluşumunda yer alan oyun arkadaşları, oyuncak ve oyun mekanları gibi başlıca ögelerin (Erc, 2017; Henninger, 1994; Sandberg 2001, 2003), OAÖ’ye verilecek yantların içeriğini oluşturması beklenmektedir. Örneğin, OAÖ’nün “oyunun işlevi ve oyunda ilgi/merak/keşif” olarak adlandırılan birinci boyutunda yer alan aşağıdaki madde incelendiğinde:

Madde 6. Oyun, çocuğun kendini ve dünyayı keşfetme aracıdır.

Katılımcının bu maddeye ilişkin görüşlerini, oyun anılarının şekillendireceği beklenmektedir. Katılımcının kendi oyunlarındaki keşif süreçlerinin ve sonuçlarının bu maddeye yönelik tutumunu belirleme potansiyeli taşıdığı düşünülmektedir.

AOÖ’nün “oyunun özgünlüğü ve amacı” başlıklı ikinci alt boyutunda yer alan aşağıdaki madde dikkate alındığında:

Madde 17. Çocuğun oyundan en üst seviyede yararlanabilmesi için özel oyuncaklara ve teknolojik materyallere gereksinimi vardır.

Katılımcının bu maddeye vereceği yanıtta, kendi oyun özgeçmişini oluşturan oyun deneyimlerinin, oyuncaklarının ve anılarının belirleyici bir etkiye sahip olacağı düşünülmektedir.

Ölçeğin “oyunun doğası ve kaynağı”" alt boyutunda yer alan aşağıdaki madde de:

Madde 8. Çocuklar yeni bir oyun keşfetmek yerine her zaman eğlenerek oynadıkları oyunları oynamayı tercih ederler.

Katılımcıların oyun hatıralarında yer alan favori oyunların ya da heyecanla keşfettikleri yeni oyunların verilecek yanıtların yapısını belirleyeceği beklenmektedir. 


\section{OAÖ Güvenirlik Sonuçları}

\section{OAÖ alt-üst grup ortalama puan farklanna dayalı madde analiz sonuçlant}

Ölçek puanlarının alt ve üst grubunun \% 27'sini oluşturan $[168 *(27 / 100)=45.36] 45$ katılımcının ortalama puan T-Test sonuçları Tablo 6' de verilmiştir.

Tablo 6. OAÖ alt ve üst \% 27'lik gruplarının madde ortalamaları t-testi sonuçları

\begin{tabular}{|c|c|c|c|c|c|}
\hline Madde & Grup & $\mathbf{N}$ & $\overline{\bar{x}}$ & Sd & $\mathbf{t}$ \\
\hline \multirow{2}{*}{1} & Alt Grup & 45 & 2.7556 & 1.28197 & \multirow{2}{*}{$-2.909^{* *}$} \\
\hline & Üst Grup & 45 & 3.5111 & 1.17980 & \\
\hline \multirow{2}{*}{2} & Alt Grup & 45 & 3.8222 & 1.33636 & \multirow{2}{*}{$-3.020^{* *}$} \\
\hline & Üst Grup & 45 & 4.5333 & .84208 & \\
\hline \multirow{2}{*}{3} & Alt Grup & 45 & 3.8444 & 1.47641 & \multirow{2}{*}{$-4.367^{* *}$} \\
\hline & Üst Grup & 45 & 4.8444 & .42403 & \\
\hline \multirow{2}{*}{4} & Alt Grup & 45 & 4.0000 & 1.02247 & \multirow{2}{*}{$-3.993^{* *}$} \\
\hline & Üst Grup & 45 & 4.7333 & .68755 & \\
\hline \multirow{2}{*}{5} & Alt Grup & 45 & 3.6000 & 1.21356 & \multirow{2}{*}{$-6.892^{* *}$} \\
\hline & Üst Grup & 45 & 4.8889 & .31782 & \\
\hline \multirow{2}{*}{6} & Alt Grup & 45 & 4.0222 & 1.35661 & \multirow{2}{*}{$-4.562^{* *}$} \\
\hline & Üst Grup & 45 & 4.9556 & .20841 & \\
\hline \multirow{2}{*}{7} & Alt Grup & 45 & 2.4444 & 1.03475 & \multirow{2}{*}{$-5.517^{* *}$} \\
\hline & Üst Grup & 45 & 3.7111 & 1.14062 & \\
\hline \multirow[b]{2}{*}{8} & Alt Grup & 45 & 2.4222 & 1.11781 & \multirow{2}{*}{$-4.042^{* *}$} \\
\hline & Üst Grup & 45 & 3.4667 & 1.32459 & \\
\hline \multirow{2}{*}{9} & Alt Grup & 45 & 3.2444 & 1.22763 & \multirow{2}{*}{$-8.378^{* *}$} \\
\hline & Üst Grup & 45 & 4.8444 & .36653 & \\
\hline \multirow{2}{*}{10} & Alt Grup & 45 & 3.3111 & 1.23991 & \multirow{2}{*}{$-6.518^{* *}$} \\
\hline & Üst Grup & 45 & 4.6667 & .63960 & \\
\hline \multirow{2}{*}{11} & Alt Grup & 45 & 2.6000 & 1.13618 & \multirow{2}{*}{$-2.543^{*}$} \\
\hline & Üst Grup & 45 & 3.2222 & 1.18492 & \\
\hline \multirow{2}{*}{12} & Alt Grup & 45 & 3.5333 & 1.09959 & \multirow{2}{*}{$-7.252^{* *}$} \\
\hline & Üst Grup & 45 & 4.8000 & .40452 & \\
\hline \multirow[b]{2}{*}{13} & Alt Grup & 45 & 3.6667 & 1.00000 & \multirow{2}{*}{$-3.487^{* *}$} \\
\hline & Üst Grup & 45 & 4.4222 & 1.05505 & \\
\hline & Alt Grup & 45 & 2.9333 & 1.21356 & \\
\hline 14 & Üst Grup & 45 & 4.1556 & 1.29607 & -4.618 \\
\hline 15 & Alt Grup & 45 & 3.5333 & 1.23583 & $231^{* *}$ \\
\hline 15 & Üst Grup & 45 & 4.7778 & .51737 & $-0.231^{m}$ \\
\hline & Alt Grup & 45 & 2.2667 & 1.13618 & \\
\hline 16 & Üst Grup & 45 & 3.3778 & 1.26651 & $-4.381^{+n}$ \\
\hline & Alt Grup & 45 & 2.3556 & 1.40058 & \\
\hline 17 & Üst Grup & 45 & 3.1556 & 1.46094 & $-2.652^{*}$ \\
\hline & Alt Grup & 45 & 3.3333 & 1.34840 & \\
\hline 18 & Üst Grup & 45 & 4.6889 & .51444 & $-0.301^{10}$ \\
\hline & Alt Grup & 45 & 3.3778 & 1.15383 & \\
\hline 19 & Üst Grup & 45 & 4.4444 & .89330 & $-4.904^{*}$ \\
\hline & Alt Grup & 45 & 2.6667 & 1.26131 & \\
\hline 20 & Üst Grup & 45 & 3.6000 & 1.26850 & $-3.500^{1.2}$ \\
\hline
\end{tabular}

Tablo 6' da verilen grup farkını ele alan T-Testi analizlerinde tüm maddelerin ölçeğe anlamlı şekilde katkı sağladıkları görülmektedir. 


\section{OAÖ madde-toplam puan korelasyonu}

Ölçeğe ait korelasyon sonuçları Tablo 7’ de verilmiştir.

Tablo 7. OAÖ alt ve üst \% 27’lik grupların madde ortalamaları t-testi sonuçlar1

\begin{tabular}{|c|c|c|}
\hline \multirow{3}{*}{ Madde } & Madde Toplam Korelasyonu & Alt $\% 27-$ Üst $\% 27$ \\
\hline & & \\
\hline & $\mathrm{r}[\mathrm{n}=172]$ & {$\left[\mathrm{n}_{1}=\mathrm{n}_{2}=34\right] / \mathrm{t}$} \\
\hline 1 & .237 & $-2.909^{* *}$ \\
\hline 2 & .345 & $-3.020^{* *}$ \\
\hline 3 & .548 & $-4.367^{* *}$ \\
\hline 4 & .503 & $-3.993^{* *}$ \\
\hline 5 & .580 & $-6.892^{* *}$ \\
\hline 6 & .622 & $-4.562^{* *}$ \\
\hline 7 & .425 & $-5.517^{* *}$ \\
\hline 8 & .282 & $-4.042^{* *}$ \\
\hline 9 & .656 & $-8.378^{* *}$ \\
\hline 10 & .529 & $-6.518^{* *}$ \\
\hline 11 & .157 & $-2.543^{*}$ \\
\hline 12 & .621 & $-7.252^{* *}$ \\
\hline 13 & .353 & $-3.487^{* *}$ \\
\hline 14 & .380 & $-4.618^{* *}$ \\
\hline 15 & .584 & $-6.231^{* *}$ \\
\hline 16 & .348 & $-4.381^{* *}$ \\
\hline 17 & .169 & $-2.652^{*}$ \\
\hline 18 & .481 & $-6.301^{* *}$ \\
\hline 19 & .377 & $-4.904^{* *}$ \\
\hline 20 & .273 & $-3.500^{* *}$ \\
\hline
\end{tabular}

Tablo 7' de, ölçeğe anlamlı düzeyde katkı sağlayan maddelerin madde-toplam korelasyon katsayılarının $.157 \leq \mathrm{r} \leq .656$ aralığında değiştiği görülmektedir. Ölçekte beş madde $.30 \leq \mathrm{r} \leq .39$ "iyi derecede bir madde" ve 10 madde de $\mathrm{r} \geq .40$ olduğu için "çok iyi bir madde" olarak değerlendirilmektedir (Büyüköztürk, 2015). Bu sonuçlara göre genel olarak ölçekte yer alan maddelerin güvenirlik açısından ölçüm aracına olumlu ve anlamlı düzeyde katk1 sağladığı söylenebilir. 


\section{OAÖ iç tutarl111k katsayısı}

Geliştirilen ölçüm aracının Cronbach Alpha değerinin .728 olarak bulunması, araştırmalarda kullanılabilecek güvenilir bir ölçüm aracı olduğunu göstermektedir (Büyüköztürk, 2015; Schmitt, 1996; Taber, 2018).

Ölçeğin güvenirlik-geçerlik analizleri sonucunda nihai ölçekte yer alan maddelerin alt boyutlara göre dağılımı Tablo 8'de sunulmuştur.

Tablo 8. OAÖ maddelerinin oluşturdukları alt boyutlar

\begin{tabular}{llllllllll}
\hline Alt boyutlar & 10 & 10 & & & \\
\hline Oyunun işlevi ve oyunda ilgi/merak/keşif & 2 & $3^{*}$ & 4 & $5^{*}$ & 6 & 9 & $12^{*}$ & 15 & 18 \\
Oyunun özgünlügü ve amac1 & $1^{*}$ & $10^{*}$ & 13 & $14^{*}$ & $16^{*}$ & $17^{*}$ & & & \\
Oyunun doğası ve kaynağ1 & $7^{*}$ & $8^{*}$ & $11^{*}$ & 20 & & & & \\
${ }^{*}$ ters kodlu maddeler & & & & & & & &
\end{tabular}

Tablo 8'de, üç alt boyutlu OAÖ’nün içerdiği 20 maddeden 11'inin ters kodlu madde özelliği gösterdiği görülmektedir.

\section{SONUÇ}

Oyun Alg1sı Ölçeğinin geliştirilme aşamasında, epistemoloji ve oyun literatüründen yararlanılarak madde havuzu oluşturulmuş ve maddelerin kapsam geçerliliği için 12 uzmanın görüşleri Lawshe tekniği ile değerlendirilmiştir. Ölçek maddelerinin KGÖ değerlerinin 12 uzman için belirlenen alt sınır değeri .56'dan büyük ve .67 ile 1.00 arasında olduğu görülerek, tüm maddelerin aday ölçekte ilk pilot uygulama için kullanılmasına karar verilmiştir.

Pilot uygulama 68 katılımcı ile gerçekleştirilmiştir, bir katılımcının yanıtlanı uç değerde olduğu için analizlere dâhil edilmemiştir ve aday ölçekte yer alan 10 maddenin, pilot uygulama sonrası yapılan ön-analizlerde, ölçeğin yapısına uygun olmadığı, geçerlilik ve güvenirlik değerlerini düşürdüğü anlaşılmıştır. Tespit edilen bu 10 maddeye ilişkin katılımcılar arasından rastgele seçilen 15 öğretmen adayı ile yüz yüze görüşmeler gerçekleştirilmesi sonucunda, tekrarlı maddelerin çelişkiye neden olduğu ve bazı maddelerinde açık şekilde anlaşılamadığı fark edilerek, bu maddelerin tümü ölçekten çıkarılmıştır. Pilot uygulama üzerinde yapılan betimsel analizlerden aday ölçeğin normal dağılım gösteren parametrik testlere uygun bir yapıda olduğu anlaşılmıştır ( p Kolmogorov-Smirnov $=.200>$.05; PShapiro-Wilk $=.885>.05 ;[-\mathrm{Z}=-1.95 \leq \mathrm{Z}($ çarp $1 \mathrm{kl} 1 \mathrm{k}=.098$, basılklık $=-.10) \leq+\mathrm{z}=+1.95]$.

Ana uygulama 172 katılımcı ile gerçekleştirilmiş olmasına rağmen dört katılımcının yanıtları uç değerde olduğu için analizlere dahil edilmemiş ve 168 katılımcının yanıtları üzerinden istatistik 
işlemleri gerçekleştirilmiştir. Ölçeğin yap1 geçerliliği için yapılacak faktör analizine uygun olduğu görülmüştür [KMO değeri=.794 > .600, Bartlett Testi Ki Kare 823.837 ve p=.000]. Ölçek maddelerinin faktör yük dağılımlarının iki madde dışında .302 ile .608 arasında değiştiği tespit edilmiştir. Buna göre ölçüm aracının madde yük değerleri kabul edilebilir alt sınırların $(>30)$ üzerindedir. Ölçeğin faktör analizi screeplot grafiğine göre üç faktörlü bir yapıda olduğu ve maddelerin faktörlere bağlanma düzeylerinin de .390 ile .772 arasında olduğu saptanmıştır. Ana uygulama sonrası ölçüm aracının oyuna ilişkin epistemik bilişleri de kapsayan oyun algısına yönelik görüşlerin \%41’ini açıkladığı bulunmuştur. Bunun yanı sıra üç faktörlü ölçekte iki alt boyutun açıkladığı varyans değerlerinin birbirine yakın olması ölçeğin dengeli bir yapıda olduğunu göstermektedir. Ölçeğin alt boyutları, ölçek maddelerinin ilişkili olduğu epistemik alt boyutlar ile oyunun özelliği, yapısı ve etkisi gibi kavramsal yaklaşımlardan hareketle, "Oyunun işlevi ve oyunda ilgi/merak/keşif”, “Oyunun özgünlüğü ve amacı” ve “Oyunun doğası ve kaynağı” şeklinde isimlendirilmiştir. Ölçüm aracının yapısal geçerliliği alt-üst \%27’lik grupların madde ortalamaları ttesti analizine göre maddelerin hepsinin anlamlı şekilde ölçeğe katkı sağladıkları bulunmuştur $(\mathrm{p}=.000)$. Bunun yanı sira hesaplanan madde-toplam korelasyon katsayılarının .157 $\leq \mathrm{r} \leq .656$ aralığında değiştiği görülmüştür. Ölçüm aracında yer alan 20 maddeden beşinin >.30 ve 10’unun da $>$ >40 korelasyon değerlerine sahip olması, ölçek maddelerinin güvenirlik açısından ölçeğe olumlu ve güçlü katkı sağladığı şeklinde yorumlanmıştır. Ölçüm aracının Cronbach Alpha değeri .728 bulunmuştur. OAÖ’nün geçerlik ve güvenirlik test sonuçları dikkate alındığında araştırmalarda kullanılmasına uygun bir ölçek olduğu ifade edilebilir.

Sonuçta; oyunun doğası ve yapısı gibi felsefi temeller dikkate alınarak geliştirilen OAÖ'nün, oyun algısını, oyun ile bilimsel bilgiyi ilişkili ve bütün olarak incelediği düşünülmektedir. Bu düşünceden hareketle, OAÖ’nün, günden güne değişime uğrayan oyunun sağllksız şekilde evrilmesine neden olabilecek, bireylerin olumsuz oyun algılarının tespitinde kullanılabilecek etkili bir ölçüm aracı özelliği gösterdiği kabul edilebilir. Bunun yanı sıra, araştırma kapsamında geliştirilen OAÖ’nin, oyunun; oyun anıları ve oyun özgeçmişi gibi sosyo-kültürel ve kişisel değerleri içeren temellerinin bireysel felsefi yaklaşımlarla değerlendirilebilmesine katkı sağlayacak bir ölçüm aracı olduğu düşünülmektedir.

\section{Sınırlılıklar ve Öneriler}

Araştırmanın örneklem grubunun toplamda 240 öğretmen adayından oluşması, çalışmanın en önemli sınırlılı̆̆ olarak görülmektedir. Bunun yanı sıra çalışmanın sadece iki üniversite ile sınırlandırılması yine örnekleme ilişkin diğer bir kısıtlama olarak kabul edilebilir. 
Geliştirilen ölçüm aracının daha büyük sayıdaki örneklem gruplarında denenerek farklı tekniklerin kullanıldığı bileşik geçerlik ve güvenirlik çalışmalarının yapılması önerilebilir. Ölçeğin kullanıldığ1 çalışmalarla bireylerin oyuna ilişkin felsefi düşünceleri ve epistemik bilişlerini de kapsayan ölçümlerle oyun algıları ilişkisel olarak incelenebilir. Bununla beraber benzer çalışmalar sınıf öğretmenleriyle de gerçekleştirilebilir. Ayrıca araştırma kapsamında geliştirilen OAÖ kullanılarak ebeveynlerin oyun algısı, oyundan beklentileri ve oyunun doğasına ilişkin görüşleri incelenebilir. Son olarak, geliştirilen ölçüm aracının yapısına paralel ölçüm araçları geliştirilerek, çocukların oyuna yönelik epistemik yaklaşımları zihinsel gelişim evreleri dikkate alınarak boylamsal olarak takip edilebilir ve süreç içinde oyun algısına ilişkin değişen düşünceleri incelenebilir.

\section{KAYNAKÇA}

Barger, M. M., \& Linnenbrink-Garcia, L. (2017). Developmental systems of students' personal theories about education. Educational Psychologist, 52(2), 63-83.

Bendixen, L. D. (2002). A process model of epistemic belief change. In B. K. Hofer \& P. R. Pintrich (Eds.), Personal epistemology: The psychology of beliefs about knowledge and knowing (pp. 191-208). Mahwah, NJ: Erlbaum.

Bendixen, L. D., \& Hartley, K. (2003). Successful learning with hypermedia: The role of epistemological beliefs and metacognitive awareness. Journal of Educational Computing Research, 28(1), 15-30.

Bodrova, E., \& Leong, D. J. (2013). Zibin araşları: Erken çocukluk eğitiminde Vygotsky yaklaşımı. (Çev. Ed. G. Haktanır). Ankara: Anı Yayıncilık.

Boss, F. (2014). Child development and early stimulation and learning resources. Save the Children, UK.

Bruner, J. S. (1975). Poverty and childhood. Oxford Review of Education, 1(1), 31-50.

Burr, B., Atkins, L., Bertram, A. G., Sears, K., \& McGinnis, A. N. (2019). If you stop playing you get old: Investigating reflections of play in older adults. Educational Gerontology, 45(5), 353364 ,

Büyüköztürk, Ş. (2002). Faktör analizi: Temel kavramlar ve ölçek geliştirmede kullanımı. Kuram ve Uygulamada Ë̈itim Yönetimi, 32, 470-483.

Büyüköztürk, Ș. (2015). Sosyal bilimler için veri analiæ̣i el kitabı. (21. Baskı). Ankara: Pegem Akademi.

Büyüköztürk, Ş., Kılıç Çakmak, E., Akgün, Ö. E., Karadeniz, Ş. ve Demirel, F. (2008). Bilimsel araștorma yöntemleri. Ankara: Pegem Akademi.

Cadinu, M. R., \& Kiesner, J. (2000). Children's development of a theory of mind. European Journal of Psychology of Education, 15(2), 93-111. 
Chinn, C. A., Buckland, L. A., \& Samarapungavan, A. L. A. (2011). Expanding the dimensions of epistemic cognition: Arguments from philosophy and psychology. Educational Psychologist, $46,141-167$.

Conley, A. M., Pintrich, P. R., Vekiri, I., \& Harrison, D. (2004). Changes in epistemological beliefs in elementary science students. Contemporary Educational Psychology, 29(2), 186-204.

Eck, J. (2017). At the end of the road - An essay on childhood play memories. International Journal of Play. Doi: 10.1080/21594937.2017.1348310.

Elder, A. D. (2002). Characterizing fifth grade students' epistemological beliefs in science. In P. R. Pintrich (Ed.), Personal epistemology: The psychology of beliefs about knowledge and knowing (pp. 347364). Mahwah, NJ, USA: Lawrence Erlbaum Associates.

Field, A. (2000). Discovering statistic using SPSS for Windows. London-Thousand Oaks-New Delhi: Sage Publications.

Gander, H., \& Gandiner, M. (2001). Çocuk ve ergen gelişimi. (Çev. A. Dönmez, N. Çelen, B. Onur). Ankara: İmge Kitabevi.

Ginsburg, K. R. (2007). The importance of play in promoting healthy child development and maintaining strong parent-child bonds. American Academy of Pediatrics, 119(1), 182-191.

Greene, J. A., Azevedo, R., \& Torney-Purta, J. (2008). Modeling epistemic and ontological cognition: Philosophical perspectives and methodological directions. Educational Psychologist, 43, 142-160.

Greene, J. A., Sandoval, W. A., \& Bråten, I. (2016). Handbook of epistemic cognition. New York, NY: Routledge.

Güneş, G. \& Batı, K. (2018). Development of a scale on scientific epistemological views and investigation of epistemological views of prospective teachers. International Journal of Research in Education and Science (IJRES), 4(2), 391-408.

Güneş, G., Şahin, V., Taşdan-Berksoy, A., \& Erkan, S. (2018). Mathematical modeling of preschool children's epistemological views. Critical Questions in Education, 9(2), 117-136.

Henninger, M. L. (1994) Adult perceptions of favourite childhood play experiences. Early Child Development and Care, 99, 23-30.

Hirsh, K. P. \& Golinkoff R. M. (2008). Why play = learning. Encyclopedia on Early Childhood Development, 1-5.

Hofer B. K., \& Pintrich, P. R. (2002). Personal epistemology: The psychology of beliefs about knowledge and knowing. Mahwah, NJ: Erlbaum.

Hofer, B. K. (2001). Personal epistemology research: Implications for learning and teaching. Journal of Educational Psychology Review, 13, 353-383.

Howitt, D., \& Cramer, D. (2011). Introduction to SPSS statistics in psychology: For version 19 and earlier. London: Pearson Education Limited.

$$
\begin{aligned}
& \text { Erken Cocukluk Calıșmalan Dergisi } \\
& \text { Cilt } 4 \cdot \text { Sav1 } 1 \cdot \text { Mart }
\end{aligned}
$$


Kienhues, D., Bromme, R., \& Stahl, E. (2008). Changing epistemological beliefs: The unexpected impact of a short-term intervention. British Journal of Educational Psychology, 78, 545-565.

Kienhues, D., Ferguson, L. E., \& Stahl, E. (2016). Diverging information and epistemic change. In J. Greene, W. Sandoval, \& I. Bråten (Eds.), Handbook of epistemic cognition (pp. 318-330). New York, NY: Routledge.

King, P., \& Kitchener, K. (1994). Developing reflective judgment: Understanding and promoting intellectual growth and critical thinking in adolescents and adults. San Francisco, CA: Jossey Bass.

Kjørholt, A. T., Matafwali, B., \& Mofu, M. (2019). The knowledge is in your ears, in the stories you hear from the grandparents': Creating intercultural dialogue through memories of childhood. In: Kjørholt, A. T., Penn H. (Eds) Early childhood and development work. Palgrave Studies on Children and Development. Palgrave Macmillan, Cham.

Kline, P. (1994). An easy guide to factor analysis. UK: Routledge.

Kostelnik, M. J., Soderman, A. K., \& Whiren, A. P. (2007). Developmentally appropriate curriculum. New Jersey: Pearson Education, Inc.

Kuhn, D. (1991). The skills of argument. Cambridge: Cambridge University Press.

Kuhn, D. (2016). A role for reasoning in a dialogical approach to critical thinking. Topoi, 1-8.

Kuhn, D., Cheney, R., \& Weinstock, M. (2000). The development of epistemological understanding. Cognitive Development, 15(3), 309-328.

Lawshe, C. H. (1975). A quantitative approach to content validity. Personnel Psychology, 28, 563-575.

Lockhard, S. (2010). Play: an important tool for cognitive development. Extensions Curriculum Newsletter from High Scope, 24(3), 1-8.

Lunn Brownlee, J., Ferguson, L. E., \& Ryan, M. (2017). Changing teachers' epistemic cognition: A new conceptual framework for epistemic reflexivity. Educational Psychologist, 52(4), 242-252.

Lunn Brownlee, J., Scholes, L., Walker, S., \& Johansson, E. (2016). Critical values education in the early years: Alignment of teachers' personal epistemologies and practices for active citizenship. Teaching and Teacher Education, 59, 261-273.

MacDonald, S. (2001). Block play. Beltsville: Gryphon House, Inc.

Mackey, A. P., Hill, S. S., Stone, S. I. \& Bunge, S. A. (2011). Differential effects of reasoning and speed training in children. Developmental Science, 14(3), 582-590.

Mascaro, O., \& Morin, O. (2015). Epistemology for beginners: Two-to five-year-old children's representation of falsity. Plos One, 10(10), e0140658.

McKillup, S. (2012). Statistics explained: An introductory guide for life scientists (2 ${ }^{\text {nd }}$ Edition). United States: Cambridge University Press.

Montessori, M. (1992). Education for human development. Clio: Oxford University Press. 
Park, J. (2019). The qualities criteria of constructive play and the teacher's role. TOJET: The Turkish Online Journal of Educational Technology, 18(1), 126-132.

Pellegrini, A. D. (2009).The role of play in human development. New York: Oxford University Press.

Piaget, J. (1964). The early growth of logic in the child. London: Routledge and Kegan Paul Ltd.

Ramani, B.G. (2005). Cooperative play and problem solving in preschool children. Unpublished Doctoral Dissertation, University of Pittsburgh.

Rodriguez, L., \& Cano, F. (2007). The learning approaches and epistemological beliefs of university students: A cross-sectional and longitudinal study. Studies in Higher Education, 32(5), 647667.

Salmon, A. K., \& Lucas, T. (2011). Exploring young children's conceptions about thinking. Journal of Research in Childhood Education, 25(4), 364-375.

Sandberg, A. (2001). Play memories from childhood to adulthood. Early Child Development and Care, 167(1), 13-25.

Sandberg, A. (2003). Play memories and place identity. Early Child Development and Care, 173(2-3), 207-221.

Saracho, O. N. (1999). A factor analysis of pre-school children's play strategies and cognitive style. Educational Psychology, 19(2), 165-180.

Schmitt, N. (1996). Uses and abuses of coefficient alpha. Psychological Assessment, 8(4), 350-353.

Schommer, M. (1990). Effects of beliefs about the nature of knowledge on comprehension. Journal of Educational Psychology, 82, 498-504.

Schommer, M. (1994). Synthesizing epistemological belief research: Tentative understandings and provocative confusions. Educational Psychology Review, 6(4), 293-319.

Schommer-Aikins, M. (2004). Explaining the epistemological belief system: Introducing the embedded systemic model and coordinated research approach. Educational Psychologist, 39, 19-29.

Seferoğlu, S. S., ve Akbıyık, C. (2006). Eleştirel düşünme ve öğretimi. Hacettepe Üniversitesi Eğitim Fakültesi Dergisi, 30, 193-200.

Sutton-Smith, B. (1971). Piaget on play: A critique. In R. E. Herron \& B. Sutton-Smith (Eds.) Child's play (pp. 326-336). New York: Wiley.

Tabachnick, B. G., \& Fideli, L. S. (2001). Using multivariate statistics (4 $4^{\text {th }}$ Edition). Boston: Ally and Bacon.

Taber, K. S. (2018). The use of Cronbach's Alpha when developing and reporting research instruments in science education. Research in Science Education, 48(6), 1273-1296. 
Taşdan-Berksoy, A., \& Güneş, G. (2018). Children's epistemological views according to their learning center preferences. Education 3-13, 46(7), 802-813.

Tavşancıl, E. (2006). Tutumlarn ölçülmesi ve SPSS ile veri analiz̨i. (3. Baskı). Ankara: Nobel.

Tuğrul, B. (2014). Oyun temelli ögrenme. Okul öncesinde özel ögretim yöntemleri. Ankara: An1 Yayınc1lık.

Vygotsky, L. S. (1967). Play and its role in the mental development of the child. Soviet Psychology, 5(3), 6-18. 